\title{
COMPARISON OF FRICTION STIRS WELDING TECHNIQUE WITH CONVENTIONAL WELDING METHODS
}

\author{
Vishwanath S Godiganur ${ }^{1}$, Shivakumar Biradar ${ }^{2}$ \\ ${ }^{1}$ Department of Mechanical Engineering, Reva Institute of Technology and Management, Yelahanka, Bangalore, \\ Karnataka \\ ${ }^{2}$ Depatment of mechanical Engineering, Bhimanna Khandre Institute of Technology and Management Bhalki; India
}

\begin{abstract}
In 1991 the welding institute (TWI) invented abstract friction stir welding(FSW) method which is an innovative solid state material joining. In the last two decade this method is one of the most important joining technologies. In aerospace and automotive industries for their joining requirements these methods are using, which mainly focus on the joining of aluminum alloys. The joining of aluminum alloys by conventional welding processes can sometimes cause serious problems. Presence of segregation and porosities and including loss of alloying elements are the difficulties recognized during the solidification process and structure. The troubles existing during the solidification related with the convention fusion welding processes can overcome by the friction stir welding which offers an alternative through solid-state bonding.
\end{abstract}

Keywords: Friction Stir Welding (FSW), conventional welding, solidification process, conventional fusion, welding $* * *$

\section{INTRODUCTION TO WELDING}

Welding may be defined as "the metallurgical joining of two metal pieces together to produce essentially a single piece of metal".

There are two groups of welding processes according to the state of the base material:

$>$ Fusion welding.

$>$ Solid-state welding.

\subsection{Fusion Welding}

Solid state welding: To melt the base metal heat is used in the fusion welding process. To make the process easy and give bulk and strength to the welded joint, to a molten pool filler metal is added. No filler metal is added in the fusion welding operation which is referred as an autogenously weld. The most broadly used welding processes are the fusion category, which can be organized into the following general groups.

Arc welding: The method in which heating of metals is accomplished by an electric arc is called as an arc welding refers to a group of welding. Pressured also apply during the process in some of the arc welding process and most of the arc welding operation used a filler metal.

Resistance welding: The heat formed from the electrical resistance to the flow of a current passing between the faying surfaces of two parts held together beneath pressure achieves coalescence which is called resistance welding.
Oxy fuel gas welding (OFW): To produce a hot flame for melting the base metal the joining processes use an oxy fuel gas, such as a mixture of oxygen and acetylene and filler metal is used.

\subsection{Solid-State Welding}

From a combination of heat and pressure or pressure alone coalescence is obtained like this joining process is called as a solid state welding. The melting point of the metals being welded if the temperature is low when heat is used In this process no filler metal is required or used.

Diffusion welding (DFW): At an elevated temperature under pressure if two surfaces are held together and the parts coalesce by solid state. Temperatures are well below the melting points of the metals (about $0.5 \mathrm{Tm}$ is the maximum), and plastic deformation at the surfaces is minimal. The primary mechanism of coalescence is solid state diffusion, which involves migration of atoms across the interface between contacting surfaces.

Friction welding (FRW): Coalescence is achieved by the heat of friction between two surfaces. The friction is induced by mechanical rubbing between the two surfaces, usually by rotation of one part relative to the other, to raise the temperature at the joint interface to the hot working range for the metals involved. Then the parts are driven toward each other with sufficient force to form a metallurgical bond. 
Ultrasonic welding (USW): In a direction parallel to the contacting surfaces moderate pressure is applied between the two parts and an oscillating motion at ultrasonic frequencies. The shear stress that removes surface films and achieves atomic bonding of the surface is obtained from the combination of vibratory forces and normal forces. Like Aluminum and copper soft materials of lap joints the USW operations are limited..

\section{WELD DEFECTS IN CONVENTIONAL WELDING PROCESSES}

Because of a history of thermal cycling and micro structural changes, a welded joint may develop certain discontinuities. The major discontinuities that affect weld quality are described below.

\subsection{Porosity}

Porosity in welds caused due to Trapped gases released during melting of the weld area and trapped gases during solidification, chemical reactions during welding, or contaminants. Most welded joints contain some porosity, which is generally spherical in shape or in the form of elongated pockets. The distribution of porosity in the weld zone may be random, or it may be concentrated in a certain region.

\subsection{Slag Inclusion}

If shielding gases are not effective during welding, contamination from the environment may also contribute to such inclusions. Inclusions: Welding conditions are important, and with proper techniques the molten slag will float to the surface of the molten weld metal and not be entrapped.

\subsection{Incomplete Fusion and Penetration:}

Incomplete fusion (or lack of fusion) produces poor weld beads.

\subsection{Weld Profile}

Weld profile is important because it can indicate incomplete fusion or the presence of slag inclusions in multiple-layer welds. Under filling results when the joint is not filled with the proper amount of weld metal Undercutting results from melting away the base metal and subsequently generating a groove in the shape of recess or notch. Unless it is not deep or sharp, an undercut can act as a stress raiser and reduce the fatigue strength of the joint and may lead to premature failure. Overlap is a surface discontinuity generally caused by poor welding practice and selection of the wrong materials.

\subsection{Cracks}

The types of cracks occurred are typically longitudinal, transverse, crater, and toe cracks. Inability of the weld metal to contract during cooling is a situation similar to hot tears that develops in castings and related to excessive restraint of the work piece.

\subsection{Surface Damage}

During welding, some of the metal may spatter and be deposited as small droplets on adjacent surfaces. In arc welding possess, the electrode may inadvertently contact the parts being welded at places not in the weld zone (arc strikes). Such surface discontinuities may be objectionable for reasons of appearance or subsequent use of the welded part. If severe, these discontinuities may adversely affect the properties of the welded structure, particularly for notch-sensitive metals. Using proper welding techniques and procedures is important in avoiding surface damage.

\subsection{Disadvantages of Conventional Welding}

1. Fusion welding processes generates fumes, gases or smoke which may cause harmful effects on operators.

2. In fusion welding process, possibility of porosity and slag inclusions are more.

3. Less process efficiency with high energy consumption.

4. Welding of dissimilar alloys and complex shapes is difficult.

5. Heat affected zone is more.

6. Distortion of work pieces and spatter is the most common problem in fusion welding.

Above discussed welding defects and disadvantages in conventional welding processes can be effectively overcome by adopting new solid state welding technique called friction stir welding.

\section{FRICTION STIR WELDING}

\subsection{Background}

The FSW process operates below the solidus temperature of the metals being joined and hence no melting takes place during the process this eliminates the defects that occur during the common fusion welding process.

Thomas (1997) focuses on his study the relatively new joining technology, friction stir welding (FSW). Friction stir welding can be used to join most aluminum alloys and surface oxide presents no difficulty to the process. On the basis of this study it was recommend that number of light weight materials suitable for the automotive, rail, marine and aerospace transportation industries can be fabricated by FSW

Maggiolino and schmid (2008) made. the corrosion resistance was compared between the AA6060-T5 and 
AA6082-T6 using two methods are friction stir welding and the metal inert gas. The experiment was done by putting the welded and polished samples in an acid salt solution. Through morphological analysis corrosion resistance was detected on the surface. The results shows that compare to the metal inert gas weld method the friction stir weld is having more resistant.

Wang et al., (2008) reported how the fatigue properties of 5052 aluminum are affected by welding processes. Based on the fatigue testing the welded joints are analyzed. In the result found the compare to the fatigue properties of TIG weld joints FSW welds joints are better.

Malarvizhib and Balasubramanian (2011) without filler metal addition AA2219 aluminium alloy square butt joints welded using gas tungsten arc welding, friction sir welding methods. The fatigue crack growth behavior effected by these welding process are reported. In the welding joints transverse tensile properties are evaluated. In the results is observed that compare to the gas tungsten arc welding and electron beam welding the friction stir welding exhibiting the superior fatigue crack growth resistance.

\subsection{Welding Principle}

The FSW is having a remarkably simple basic concept. Into the abutting edges of sheets or plates, a non consumable rotating tool with a specially designed should and pin is inserted and subsequently traversed along the joint line. For the tool and work piece figure 3.1 illustrates process definitions. Most definitions are self-explanatory, but advancing and retreating side definitions require a brief explanation. Advancing and retreating side orientations require knowledge of the tool rotation and travel directions. In Fig. 3.1, the In the counter clockwise direction FSW tool rotates and travels into the page. The advancing side is on the right in fig. 3.1, where the direction of tool travel and tool rotation are same, and side retreating is on the left, where the direction of tool travel and tool rotation is opposite.

Suppression of hot metal, heating of the work piece and movement of material to produce the joint, these are the three primary function of the tool. From the severe plastic deformation of the work piece and rotating tool pin and shoulder, heat is produced within the work piece by friction. around the pin material softens due to the localized heating and combined with the tool rotation and translation, because of this material move from the front to the back of the pin, due to this tool moves forward and filling the hole in the tool wakes. The metal flow to a level equivalent to the should position controlled by the tool shoulder. A solid state joint is produced due to the effect of tool action and influence on the work piece.
Movement of material around the pin due to the various geometrical features complex, with gradients in strain, temperature, and strain rate With gradients in strain, temperature and strain rate friction stir welding from the schematic diagram is complex. From this different thermo mechanical histories and is not homogeneous due the nugget zone microstructure. One of the major benefits of the solid state welding technique, in the nugget by the intense plstaic deformation at elevated temperature by the full recrystallized, equiaxed, superior particle microstructure produced. The fine grain microstructure produces excellent mechanical properties, fatigue properties, enhanced formability, and exceptional super plasticity.

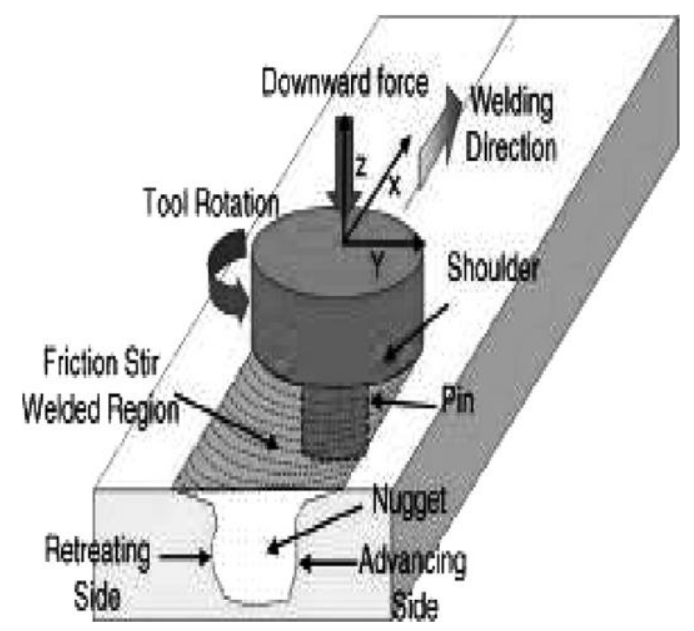

Fig 1 Schematic drawings of friction stir welding

For FSW of butt and lap joints there is no special preparation is needed. Irrespective of the surface condition of the plates easily two clean metal plates can joined in the form of lap or butt joints.

The solid state welding is the process where coalescence is produced at temperatures below the melting temperatures of the base metal without any need for the filler material or any inert ambience in many cases. Examples of solid state welding are friction welding, explosion welding, forge welding, hot pressure welding and ultrasonic welding. The three important parameters time, temperature and pressure individually or in combinations produce the joint in the base metal.

The joint in the base metal can be formed by three main parameters temperature, pressure and time independently or in combination. Due to the melting and solidification of the metal there are less defects since metal in the solid state welding does not achieve its melting temperatures. The original properties retained in the solid state welding the metals being joined as in the joint melting does not occur. Compare to fusion welding techniques it is having a very small heat affected zone, where most of the deterioration of 
the strength and ductility begins. Compare to fustian welding with easily dissimilar metals can be joined.

\subsection{Process Parameter of FSW}

While the general principles of the effect of process variables on the friction stir welding process have much in common with other welding processes, there are many factors which can affect output response. The main process variables in friction stir welding are listed as follows:
Tool rotational speed
Welding speed
Shoulder diameter
Pin diameter and profile
Axial force
Tilt angle
Work piece material
Shoulder and pin material

All these variables may affect the characteristics of the weld joint significantly. Tool rotation speed is the rotation speed of friction stir welding tool and can be directly related to the frictional heat generation [Oertelt et al. ,2001]. welding speed is preferred to transverse speed, which is the rate of travel of tool along the joint line. Tool revolving speed and welding speed choose whether enough heat input is being supplied to weld so as to favorably affect the weld characteristics. Forces are important parameters parts of friction stir welding technology. The defect free weld is decided by the use of proper tool design. Tool consists of three parts, these are shoulder diameter, pin and shank. Pin having small diameter and plunged into the work piece materials completely. The pin is accountable for suitable stirring of the material and transportation of plasticized material from the leading edge of the tool to trailing edge of the tool Shoulder is part of the tool which produces most of heat due to its rubbing with work piece surface.

All these variables act to determine the outcome of the welding process. The main interest in studying the effect of the process variables lies in understanding the effect of the process on joint properties, including static mechanical and metallurgical properties, with the goal of maximizing productivity, performance and reproducibility. The welding process affects these joint properties primarily through heat generation and dissipation, so primary attention should be given to the effect of the welding process variables on heat generation and related outcomes.

In a FSW material flow is complicated and information is limited about the deformation process . the material flow during FSW is influenced by many other factor also. For example tool geometry, plunge depth material type etc. several indeepended deformation process in the FSW.

\subsection{Advantages of Friction Stir Welding Process}

$>\quad$ Friction welding is environmentally friendly process as it does not generate fumes, gases or smoke.

$>$ Friction welding is suitable for quantities ranging from prototype to high production.

> As friction welding is a solid state process, possibility of porosity and slag inclusions are eliminated.

$>\quad$ Welding of unequal cross sections can be done by friction welding process.

$>\quad$ It allows choosing of either manual loading or optional automated loading.

> Dissimilar materials which are normally not compatible for welding can be friction welded.

$>$ Friction welding is consistent and repetitive process.

$>\quad$ It consumes low energy and low welding stress.

$>$ It reduces raw material cost with bi-metal applications.

$>\quad$ It reduces maintenance cost.

$>\quad$ It reduces machining labor, which in turn increases capacity and reduces perishable tooling cost.

$>\quad$ It reduces cost for complex forgings or castings.

$>$ Self-cleaning action of friction welding reduces or eliminates surface preparation cost or time for some material combinations.

$>\quad$ In case of friction welding, joint strength is equal to or greater than parent material.

$>\quad$ It creates a narrow heat affected zone.

$>\quad$ It has accurate control over post welds tolerances.

$>\quad$ It is highly precision and repeatable process.

$>\quad$ No flux or filler metals or gases are required in case of friction welding.

$>\quad$ Create cast or forge like blanks, without the expensive costs of tooling and the minimum quantity requirements.

$>\quad$ Friction welded joint can withstand high temperature variation.

\section{CONCLUSIONS}

Main categories of welding and different type of welding defects in conventional welded joints are discussed in this unit. The major problems identified in conventional welding are associated with solidification process and structure, including loss of alloying elements and presence of segregation and porosities, blow hole, crack formation in the weld joint. These problems can be solved by adopting new welding technique Friction stir welding (FSW) which offers an alternative through solid-state bonding with high joint efficiency, which eliminates all these problems of solidification associated with the conventional fusion welding processes.

\section{ACKNOWLEDGEMENTS}

With deep gratitude we express our sincere thanks to Sachinkumar Patil, Assistant Professor Department of Mechanical Engineering, REVA ITM Bangalore for his 
guidance and untiring efforts for this work. We humbly express our thanks to HOD, Department of Mechanical Engineering and the Principal, REVA ITM Bangalore for their support.

\section{REFERENCES}

[1] Thomas W. M , Nicholas E. D., 1997. Friction stirs welding for the transportation industries. Materials \& Design 18(4-6): 269-273.

[2] Maggiolino S., Schmid C., 2008. Corrosion resistance in FSW and in MIG welding techniques of AA6000. Journal of Materials Processing Technology 197: 237240.

[3] Malarvizhia S., Balasubramanian V., 2011. Effects of welding processes and post-weld aging treatment on fatigue behaviour of AA2219 aluminium alloy joints. Journal of Materials Engineering and Performance 20(3): 359-367.

[4] Wang X., Wang K., Shen Y., Hu K., 2008. Comparison of fatigue property between friction stir and TIG welds. Journal of University of Science and Technology Beijing, Mineral, Metallurgy, Material 15: 280-284

[5] Cabello M., Ruckert G., Huneau S. B., Marya S., 2008. Comparison of TIG welded and friction stir welded $\mathrm{Al}-$ $4.5 \mathrm{Mg}-0.26 \mathrm{Sc}$ alloy. Journal of Materials Processing Technology 197 (1-3): 337-343.

[6] Elangovan K., Balasubramanian V., 2008. Influences of tool pin profile and tool shoulder diameter on the formation of friction stir processing zone in AA6061 aluminium alloy. Materials and Design 29: 362-373.

[7] Dawes C., Wayne T., "Friction stir joining of aluminium alloys", TWI Bulletin, No.6, 1995. 